\title{
Research on Key Technologies of High-yield and High-efficiency Production in Coal Enterprises
}

\author{
Liu $\mathrm{Na}$ \\ China National Institute of Standardization, Beijing 100191, China
}

\begin{abstract}
According to the production characteristics of coal enterprises in China, this paper defines the essential connotations and main characteristics of high-yield and high-efficiency coal enterprises from the perspectives of high quality and high efficiency. On this basis, this paper analyzes the key elements and points to achieve high-yield and high-efficiency production in coal enterprises, and then constructs the key technology system of high-yield and high-efficiency production in coal enterprises in China, so as to provide reference for the improvement of the overall production level in coal enterprises.
\end{abstract}

\section{Foreword}

As the basic guarantee of national and regional development, energy is directly related to the development of social and economic, and has always been a "hot spot" of human concern. China is the country with the most abundant coal reserves except for the United States and Russia. At present, China is not only a big coal producer in the world, but also a big coal consumer. Since 1978, China's coal production and consumption account for more than $68 \%$ of the world's overall level [1]. As a non-renewable energy, how to be produced in a high-yield and efficient production way in coal enterprises is very important. In this paper, combined with advanced technology and management method, the way to achieve high-yield and efficient production in coal enterprises is analyzed from the perspectives of high-quality and high-efficiency.

\section{Theory of high yield and high efficiency mine construction}

\subsection{Meaning of high output and high efficiency mine}

The so-called high output and high efficiency mine refers to the mine that meets the requirements of reasonable layout, centralized production, high mechanization level and high coal output, high efficiency, good safety level and good efficiency, namely the "three high and two good" mine. And the "two high" mines especially meet the requirements of high output and high efficiency. The construction of high-yield and high-efficiency mine is an inevitable choice under the situation of the current coal development. Its connotation is to focus on the core goal of economic benefits. Through the adoption of advanced production and mining technology, mechanized means, scientific management, the high output and high efficiency mine can strengthen the control of production cost and improve production efficiency and benefit.

\subsection{Characteristics of high yield and high efficiency mine}

Through the investigation and analysis of the actual production situation in advanced coal enterprises at home and abroad, it is found that the high output and high efficiency mine has the following characteristics.

\subsubsection{Improvement of the level of per unit area yield and tempo of working face}

Improving the level of unit yield and its digging is an important way to achieve high output and high efficiency mine construction. The improvement of the level of per unit area yield and tempo depends on the improvement of technical equipment and personnel quality. It can also be achieved by reducing the failure rate of equipment, ensuring the continuous production of working face and improving the utilization rate of working hours $[2,3,4]$.

\subsubsection{Optimization of production layout and reasonably centralized production}

The production environment is complex and the working procedures are various in mine. It is necessary to ensure reasonable production layout as support in order to achieve safe and efficient production. Therefore, reasonable production layout and centralized production are the main means to construct the high output and high efficiency mine. Through the centralization of person, equipment and other resources, a large-scale centralized production is formed to provide good production conditions for the mining area. At the same time, 
combined with the optimization of the organizational system and reasonable cost control, large-scale centralized production is able to ensure the steady improvement of efficiency and benefit.

\subsubsection{Improvement of the mechanization degree and comprehensive production capacity in coal mine}

Improving the mechanization degree of coal mining is one of the important premises to achieve high output and high efficiency. Mechanized coal mining which can centralize production, high power and reliability mechanized mining equipment is able to greatly improve the production capacity of the working face. Since Britain put the first comprehensive mining equipment into use in 1954, the world's leading coal producers have realized mechanized mining. Since the 1980 s, the level of mechanized mining in China has been increasing, and current mechanization level is nearly $100 \%$.

\subsubsection{Timely promotion and application of advanced technology, process and equipment}

The construction of high output and high efficiency mine needs enterprises to actively absorb the latest technical equipment and scientific research achievements in the field of coal, and turn them into productivity, so as to ensure that they can provide timely technical support for the coal mine. Therefore, it is necessary for coal mining enterprises to strengthen the close contact with universities and scientific research institutions, absorb advanced technology and enhance the innovation ability of enterprises [5, 6].

\subsubsection{Improvement of employment efficiency through the adoption of modern management means and methods.}

While fully considering the improvement of production efficiency, the high output and high efficiency mine should also strengthen the internal control of the enterprise and actively adopt modern management means to provide guarantee for the high efficiency.

\section{Analysis on key factors of high production and high efficiency in coal enterprises}

According to the theory of high yield and high efficiency mine construction, high-yield and high-efficiency mine takes the pursuit of "high efficiency" and "high benefit" as two starting points, relying on the advanced coal mine production technology and management means, and finally realizes the purpose of high yield and high efficiency. Among them, economic benefit is the ultimate goal of coal mine production and operation, and mining efficiency is the basic guarantee of economic benefit.

The improvement of coal mine production efficiency is related to every step of daily production that must be improved through the whole process of mining, digging, machinery, transportation and communication to ensure the realization of high efficiency. At the same time of using advanced technology in coal mine production, scientific and reasonable management mode should be adopted to effectively plan all aspects of resources of coal mine, such as human resources, equipment, production and so on, and finally achieve the goal of high benefit.

Therefore, the following contents should be considered for high-yield and efficient production of coal enterprises:

\subsection{Application of advanced technology based on production process in coal mine}

The advanced production technology of coal mine plays a key role in improving the production efficiency of coal mine. The continuous introduction of modern science and technology can also fully guarantee the personal and property safety, and improve the comprehensive strength of coal mine. Therefore, it is necessary to actively eliminate the backward technology and adopt the advanced production technology in order to achieve efficient production. Because the production conditions of coal mine are complex, and there are many technologies and processes involved in the production process, when analyzing the advanced technology and process of coal mine, the four key production processes of coal mine, i.e. mining, driving, excavate and transportation are analyzed to ensure the comprehensiveness and rationality of the analysis.

\subsection{Production management system}

Production management is mainly a series of efficient production management systems established to assist coal mine production, including production scheduling management, production succession plan management, geological survey management, equipment management, mechanical and electrical management and other advanced systems. High yield and high efficiency coal mine must be more systematic and scientific and meet the development requirements of modern coal industry, so as to establish an effective coal mine high efficiency production system. 


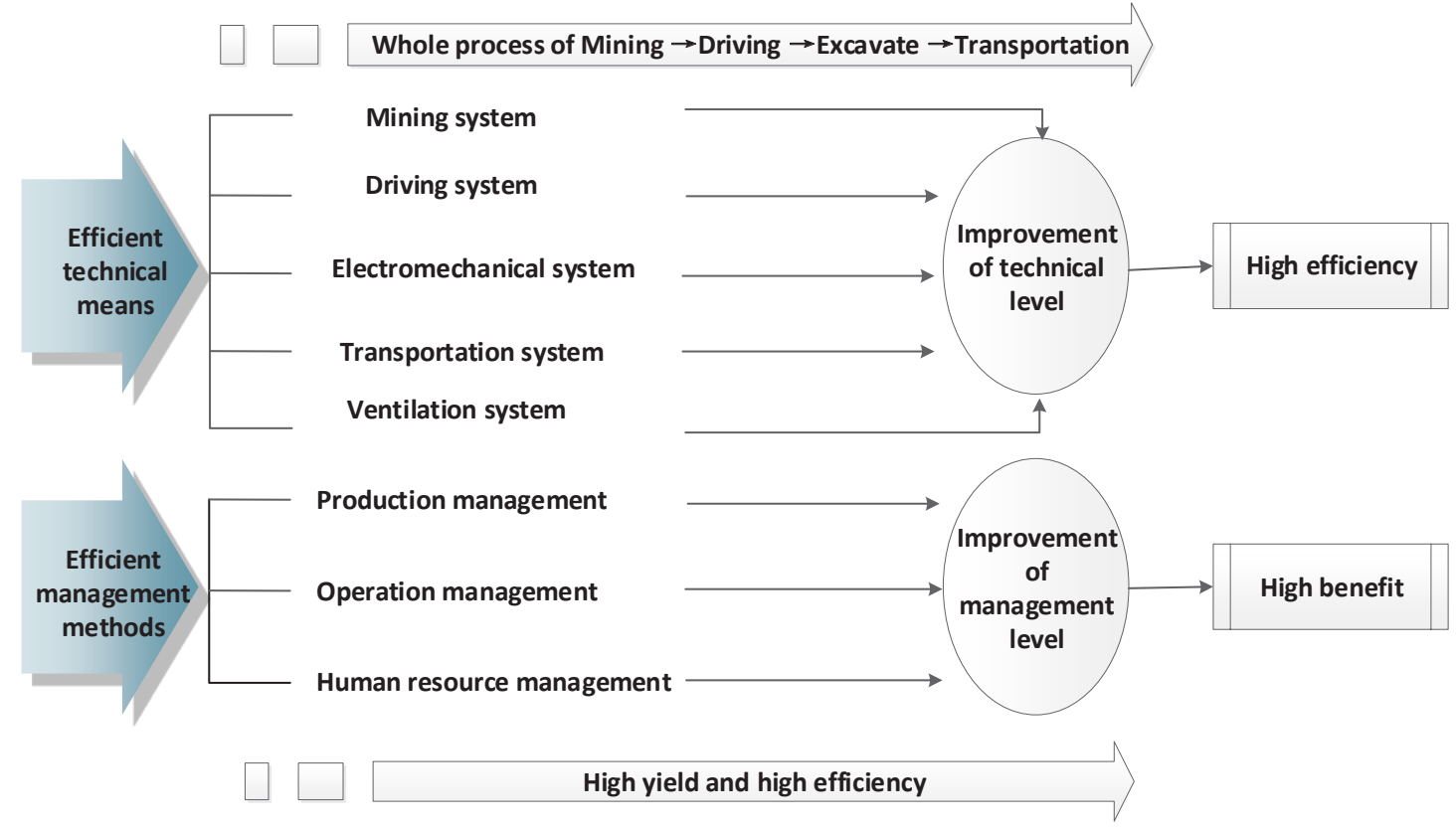

Fig.1. Construction system of high-production and high-effect world class coal mining

\subsection{Operation management measures}

Operation management mainly refers to the management methods serving the overall operation and coordination of the coal mine, especially including but not limited to the financial related management system directly related to the profits and benefits of the coal mine in order to achieve the ultimate profit purpose. It mainly includes financial management, cost management, budget management and other contents, as well as benchmarking management, lean management, performance management and other innovative management systems.

\subsection{Human resource management system}

Human resource management mainly includes personnel recruitment and dismissal, training management, post evaluation system and salary management. It is necessary to enhance the professional skills of employees through pre-job training, assign appropriate positions to personnel, motivate employees completely through the effective job evaluation system and matching salary.

\section{Key technology system of high production and high efficiency in coal enterprises of China}

High yield and high efficiency coal mines should pay attention to the application of modern technology and equipment. In addition to the more common production technology currently used in coal mines, the following advanced technology and management measures should be strengthened according to their own conditions to improve production efficiency and economic benefit.

\subsection{The advanced technology of high production and high efficiency coal mine construction mainly includes:}

\subsubsection{Mine field development layout}

The layout of mine field development can adopt the strip layout of main roadway without panel area. No panel division mode cancels the traditional panel layout mode, simplify the production link of the mine and improve the intensive degree of the coal mine by directly arranging long strip mining on both sides of the main roadway. The strip layout is arranged according to the extension direction of the coal seam, and the main roadway is divided into several inclined strips with independent production systems and are suitable for arranging the inclined longwall mining face along the coal seam strike on both sides of the main roadway. Inclined strip simplifies roadway layout and transportation system and reduces coal pillar loss.

\subsubsection{Underground mining}

The key technologies of high yield and high efficiency underground production include the layout of double lane and multi lane in fully mechanized working face, the reasonable increase of working face length and continuous advancing length, the optimized selection and reasonable matching of main equipment, the optimization of high-yield and high-efficiency long wall fully mechanized mining technology, the rapid moving technology of multi-channel fully mechanized working face in auxiliary lane and the rapid driving of continuous coal mining machine 


\subsubsection{Mine production system}

The key technologies of the mine production system include continuous and automatic monitoring of coal transportation from ground to underground, auxiliary transportation of trackless tyred vehicle, ventilation system with large section, multi-channel, low negative pressure and large air volume, remote power supply for ground box transformer and underground transformer and automatic water supply and drainage.

\subsubsection{Coal shipment}

The automatic control and rapid loading system can be adopted for the high output and high efficiency coal loading. The electric eye is used for the automatic loading instead of the coal release button. The limit switch is used to control the height of the loading chute to realize the automatic operation. The loading quality is high, the effect is good, and the workload of the flat coal is reduced.

\subsection{The advanced management measures of high production and high efficiency coal mine construction mainly include:}

\subsubsection{Production management}

The management of production succession plan can realize daily plan making and limited information transmission by establishing an online operation platform, which can meet the main needs of graphical succession plan making, succession plan collaboration and long-term succession plan research. Production scheduling management needs information technology to achieve efficient scheduling and command management mode. The post standardized operation management that integrates the concept of "process management", decomposes each operation procedure and action of the current operation method, improves the operation process, thus forms an optimized operation procedure, and gradually achieves the safe and efficient operation effect.

\subsubsection{Operation management}

The comprehensive budget management system should be established in coal mine budget to realize the reasonable allocation plan of resources and the arrangement of overall economic plan. Cost management should realize effective management and control of coal mine operation cost by establishing four-level accounting system (i.e. company, mine department, district team, team), quota management and team accounting. Performance management should establish five types of performance evaluation system (i.e. intrinsic safety type, quality benefit type, scientific and technological innovation type, resource saving type, harmonious development type), so as to achieve the purpose of effective evaluation of employees. Centralized financial management and control needs to unify accounting business, tax management, budget system and financial system, centralized management of funds and financial personnel and establishment of corresponding information system. Through lean management and benchmarking management and other advanced management methods, the pursuit of maximum economic benefits can be realized and the development of coal mines can be promoted to the world's advanced level.

\subsubsection{Human resource management}

For staff training, a targeted four-level training system shall be established at company level, mine department level, district team level and team level, and an operation training room shall be set up to carry out simulation training for the staff. The mine cadre training system shall carry out training for the quality required by leaders at all levels, so as to improve the skills of managers. The post evaluation and salary optimization system design a reasonable salary system according to the contribution degree of post value and the difference of personal ability, and enhances the fairness of income distribution.

\subsubsection{Specialized management and control mode}

Through the establishment of specialized service units, the specialized management and control mode realizes highly unified and centralized management and full sharing of resources, which can improve the operation efficiency, reduce the operation cost and enhance the core competitiveness. Taking SHENGDONG group as an example, at present, its specialized service units include 14 specialized centers and units, including development preparation, moving and reversing, equipment maintenance, equipment management, material supply, washing and loading, geological survey, information, vehicles, power supply, mine logistics and property management, business accounting, human resource service, etc., and the service scope has included all the coal mines belong to it. 


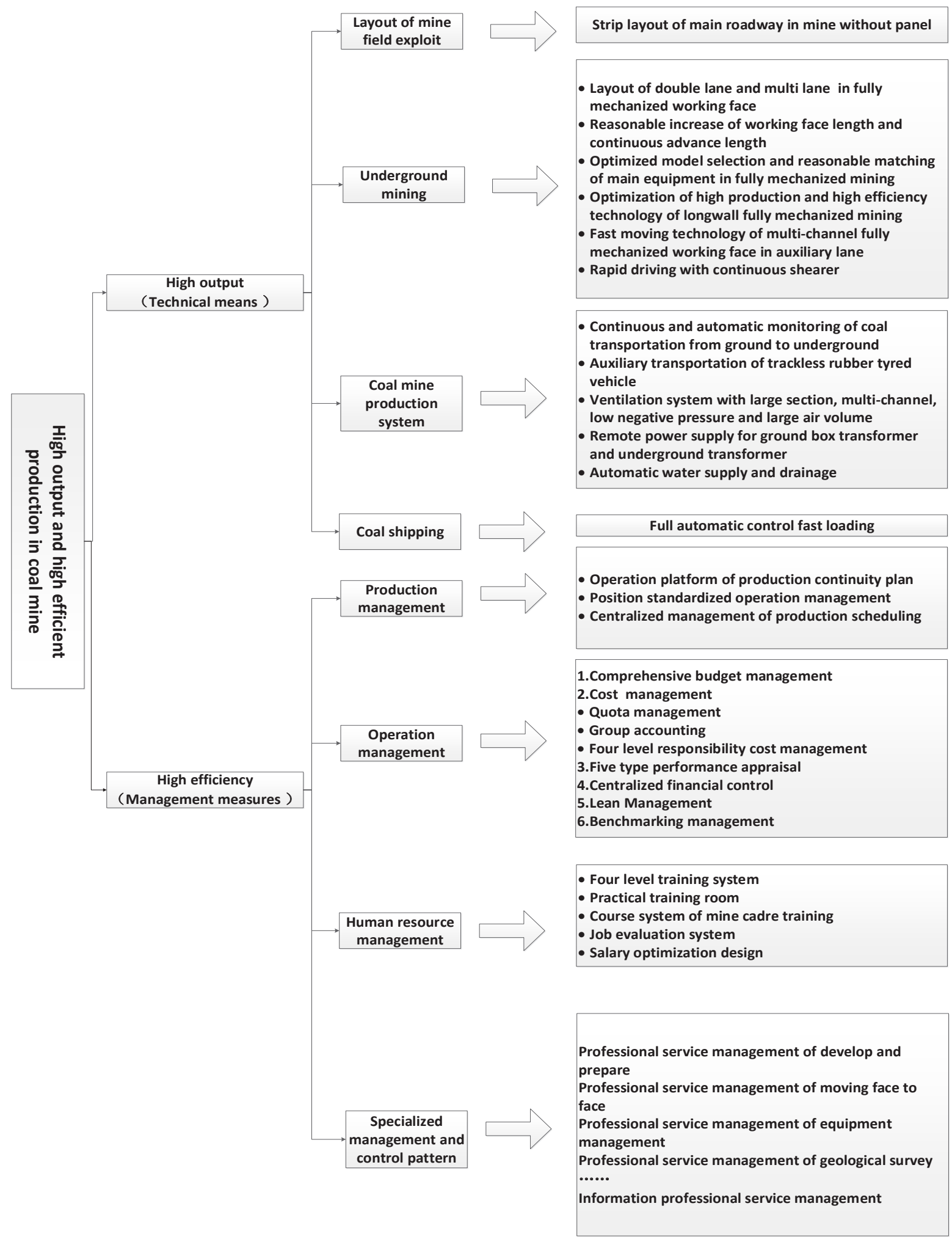

Fig.2. The key techniques for the high-production and high-efficiency coal mining

\section{Conclusion}

In this study, field research and theoretical analysis are combined to summarize the advanced experience and technical means of production management in coal enterprises. At the same time, through the establishment of the key technology system of high-yield and high-efficient production of coal enterprises, to provide reference for coal enterprises to achieve high-quality and efficient production from the perspective of technology and management.

\section{References}

1. Jiangong Liu, Qingbiao Zhao, Feng Liu et al. Theory 
and technology of the construction of ecological mine $[\mathrm{M}]$. Beijing: Chin Coal Industry PublishingHouse, 2013:1-5.

2. National Bureau of Statistics of the People's Republic of China, China Statistical Yearbook 2013[R]. China Statistics Press, 2013: 120-145.

3. National Energy Administration. Announcement of National Energy Administration (No. 3, 2018). 2018-04-08.

4. Caineng Zhou, Zhi Yang, Shipeng Huang et al. Resource types, formation, distribution and development prospects of coal-derived natural gas [J]. Petroleum Exploration and Development, 2019, 46(03):433-442.

5. Zhaofeng Wang, Weiwei $\mathrm{Su}, \mathrm{Xu}$ Tang, et al. Influence of water invasion on methane adsorption behavior in coa1[J]. International Journal of Coal Geology, 2018, 197(1):74-83.

6. Jinfeng Liu, Peter A. Fokker, Colin J. Peach, et al. Applied stress reduces swelling of coal induced by adsorption of water[J]. Geomechanics for Energy and the Environment 2018, 16:45-63. 